Columbia International Publishing

American Journal of Agricultural Science and Technology

(2014) Vol. 2 No. 2 pp. 74-99

doi:10.7726/ajast.2014.1008

Review

\title{
A Review of Methods to Measure Animal Body Temperature in Precision Farming
}

\author{
Nadine Sellier ${ }^{1}$, Elodie Guettier ${ }^{2}$, and Christophe Staub2* \\ Received 28 May 2014; Published online 3 January 2015 \\ (C) The author(s) 2014. Published with open access at www.uscip.us
}

\begin{abstract}
Automation of phenotypic measurements of livestock has become a more important goal for scientists and also for farmers who need a more precise, real-time knowledge of their animals. Among physiological measures, body temperature and its variations are key indicators of the physiological health and well-being of animals. Although measuring the body temperature may seem a trivial matter, its implementation is faced with many difficulties both at biological and technological levels in a field of constant progress. Today, there are many studies reporting taking temperature measurements without restraining animals. The present report focuses on the two main approaches to temperature measurements that use direct contact or radiation sensors. Specifically, we investigated the use of thermocouples, thermistors and infrared radiation sensors. A wide literature review using one of these techniques was conducted in which different animal species, different purposes, different experimental designs, various equipments, and different devices and gold standard methods are discussed. These technologies will continue their dizzying development, leading to new communication protocols, sensors miniaturization and a more efficient management of energy. These developments will have a direct impact on the increase of reading distances and the amount of information stored. In response to the request of farmers and researchers, integrated monitoring systems are already marketed with user-friendly interfaces and softwares for complex data storage and treatments.
\end{abstract}

Keywords: Remote temperature; Telemetry; Livestock monitoring; Precision farming

\section{Introduction}

Modern agricultural practices and veterinary research are increasingly converging toward complete control of all environmental conditions during an animal's life span. Physiological parameters must be precisely known and monitored continuously in order to detect the smallest changes, which will reflect physiological health and well-being of animals. Quality of production or experimental results depends on the reactivity of farmers or technicians in charge of animal

*Corresponding e-mail: Christophe.Staub@tours.inra.fr

1 INRA, UMR 1355 Sophia-Agrobiotech, F-06903 Sophia-Antipolis, France

2 INRA, UE 1297 Physiologie Animale de l'Orfrasière, F-37380 Nouzilly, France 
Nadine Sellier, Elodie Guettier, and Christophe Staub / American Journal of Agricultural Science and Technology

(2014) Vol. 2 No. 2 pp. 74-99

husbandry. Among all physiological data that are sensitive to the tiniest changes in domestic animals, temperature is the most classically measured and the most related to an important number of varied functions of the organism, such as nutrition, reproduction, activity, stress responses, and obviously preservation of health. These functions, and more importantly, their variations can be assessed through close monitoring of the animal's body temperature. Although temperature is easier to measure than other complex traits, because of extensive research on the instruments and physical principles of temperature evaluation, there are still some complications when measuring animal's temperatures, such as the necessity to handle and restrain animals, which will limit the number of animals being measured in a defined time span. In the context of modernization of both breeding practices and the emergence of new research directions towards animal systematic phenotyping, the need for reliable automated tools allowing continuous measurements is more and more acute. The purpose of this paper is to make a large review of practices, experiences and results, based on a bibliographic study, related to automatisation of temperature recordings in the main husbandry species, and to give help to biologists, practitioners, farmers and animal caretakers in the choice of the devices the most adapted to their own needs.

\section{The Limits of the Assessment of Body Temperature}

\subsection{About homeothermy}

Thermoregulation is the process of maintaining body temperature homeothermy in mammals and birds by modulating two main processes. The first process is the intense heat production due to the activity of the principle organs such as brain, heart, and viscera (liver, kidneys). Normal running of these organs generates the greater part of body heat (about 60\%), and thus defines the body core temperature. The second process of thermoregulation consists of the complex balance between heat production, especially by the muscles, and the process of dispersion and removal of central heat. Central heat is primarily removed controled by the hypothalamus via blood flow regulation by conduction, radiation, convection, and evaporation. This heat flux obviously depends on the surrounding conditions, and leads to the notion of peripheral temperature with an underlying notion of gradient. Consequently, peripheral temperature depends on core temperature, environmental conditions and the peripheral blood system regulation. In many endotherms, parts of the body surface are relatively poorly covered in coat, or even entirely devoid of insulation ; these areas can be considered "thermal windows" that present a greater range of cutaneous blood flow. Known examples of these "thermal windows" include the ears, feet and nose of mammals, and the bills, feet and facial skin (comb and wattles) of birds (Autio et al., 2007; Tattersall and Cadena, 2010). A wide and accurate analysis of heat conduction and transfer models is made by McCafferty et al. (2011) and Renaudeau et al. (2010) showing the varied causes, mechanisms and consequences of heat stress in livestock.

As a result of the complexity of this thermoregulatory system, the variations in body temperature are dependent on a number of internal and external causes. For given thermoneutral environmental conditions, modulations of body temperature are directly and inherently subjected to circadian rhythms (Lowe et al., 2001; Piccione et al., 2005). Sexual status and rhythms, especially estrus, pregnancy, parturition, and lactation, also influence body temperature (Berry et al., 2003 ; Aoki et al., 2005; Bewley et al., 2008; Cooper-Prado et al., 2011). 
Nadine Sellier, Elodie Guettier, and Christophe Staub / American Journal of Agricultural Science and Technology

(2014) Vol. 2 No. 2 pp. 74-99

Essentially, the most important biological functions have major effects on temperature, such as alimentation and digestion (Mader et al., 2010; Montanholi et al., 2010), exercise, and any kind of muscular activity (Green et al., 2005; Angle and Gillette, 2011).

Body temperature is also modified when animals are placed in situations of stress or pain, as shown by McCafferty (2013) in birds and Stewart et al. (2007, 2008 and 2010) in calves, who attributed this modification to a consequence of the alterations in blood flow through capillary beds, mediated by sympathetic regulations. Even the expression of stress can generate changes in body temperature, as mentioned by Moe et al. (2012), when a peripheral temperature drop was observed in adult laying hens when there was a mild stress exposure to their offspring.

Lastly, all the mechanisms involved in the fight against external pathogenic aggressors, during an infection, or even locally when there is a tissue inflammation will lead to hyperthermia. Consequently, body temperature is a criterion of great interest and needs to be monitored as closely as possible, in an attempt to increase early detection and treatment of a number of economically important illnesses, such as cattle foot and mouth disease (Rainwater-Lovett et al., 2009), bovine respiratory disease (Schaefer et al., 2012), horse lameness (Eddy et al., 2001), classical swine fever virus (Lohse et al., 2010) or poultry bumblefoot (Wilcox et al., 2009).

Environmental conditions such as ambient temperature, humidity, wind, sun, shade, and air movements have a strong impact on body temperature (Lowe et al., 2001; Faurie et al., 2001; Berry et al., 2003; Davis et al., 2003; Green et al., 2005). Continuous measurements of temperature could also be an interesting and efficient tool to prevent heat stress (Laburn et al., 2002; Renaudeau et al., 2008; Green et al., 2009), or for genetic selection of animals more tolerant to ambient conditions or extreme variations (Dikmen et al., 2009). A brief review of the advantages of continuous temperature monitoring in cattle has been made by Schutz and Bewley (2009).

Today, a system which utilizes the benefits of monitoring the body temperature of livestock is being spread among farmers and aims to detect the first signs of parturition and thus to prevent potential incidents. For that purpose, many companies are already developing and selling completely integrated systems, based on sensors placed in the vagina of pregnant females a few days before parturition is expected. An alert is automatically send to farmers via their mobile phones, when the sensor is expelled from the animal's body and the temperature changes from the internal temperature of the cow to the ambient environmental temperature.

\subsection{Contribution of technological progress}

This overview of body temperature measurements leads to the following questions: What is body temperature? What is the best way to measure body temperature? Where is the best location to measure it, depending on what kind of metabolic function or what purpose may be of interest to the farmer or the scientist?

For many years, body core temperature has been used as a reference by veterinarians and farmers to represent the basic status of the animal at rest or as a sign of disease, if abnormal. Most often, the body core temperature was easily obtained through use of a rectal thermometer. Basal rectal temperatures are quite well known within all species, and references are defined for different 
Nadine Sellier, Elodie Guettier, and Christophe Staub / American Journal of Agricultural Science and Technology

(2014) Vol. 2 No. 2 pp. 74-99

status of animals in order to detect many problems, primilary health problems. But even the relatively simple task of obtaining a temperature through rectal thermometer requires the animal to be restrained, often for more than a minute; this is likely to cause a stress response, resulting in stress-induced hyperthermia, which would decrease the likelihood of accurate assessment of body temperature (Torrao et al., 2011). With the development of agronomic and veterinary research, the need for more sensitive methods, continuous and connected to specific physiological functions appeared. Telemetric resources are reported to reduce stress and physiological disturbance of animals by removing the influence of the measurement procedure, and thereby improving the quality of data. These ressouces allow real-time processing of collected data and precise assessment of the impact of environmental or operational changes (Hamrita and Paulishen, 2011). Such technologic advances will permit automatic data recording, standardization of measurement conditions, and will help significantly increase the number of monitored animals, providing more data about animal status and responses to environmental variations. Biotelemetry reduces bias and observation influence, therefore contributing to more accurate measurements (Eigenberg et al., 2008). The benefits of biotelemetry have improved a wide range of applications and assisted in the development of many new possibilities for accurate temperature measurements. (Hamrita and Paulishen, 2011).

\subsection{Definition of temperature zone measurements}

As these tools develop and more questions about temperature measurements are asked, researchers are investigating the significance of the temperature at a certain location of the animal's body. Even though rectal temperature is assumed to reflect body core temperature, surface temperature may be considered to be the balance between physiological phenomenon and environmental conditions. Peripheral temperatures are highly affected by a change in the blood flow, from the core to outside, which is done in order to dissipate the surplus heat produced by physiological internal processes. However, peripheral temperatures are also highly affected by the ambient external conditions, which will strongly influence the temperature gradient between the core and periphery. An animal's blood vessels will dilate in response to a hot environment; this results in peripheral temperatures being closer to the core temperature (Torrao et al., 2011). Consequently, there is no evidence than subcutaneously implanted microchips will accurately estimate body core temperature.

In order to avoid possible bias during the interpretation of the results, data is generally analyzed relative to "reference data", taken from a control group or at a previous stage from the same animal used during the study. Additionally, measurements should be interpreted in the context of the measurement site (Hanneman et al., 2004).

In order to clarify the tables which describe the methods discussed in this review, we will arbitrarily define three zones of the body from which the temperature measurements are taken:

- $\quad$ Body core temperature: assumed to reveal the internal temperature of the body, very close to the main organs, heart, brain, and viscera. Classically, this measurement is assumed to be evaluated by rectal, vaginal, tympanic, vascular, intra-peritoneal, or digestive tract sensors. 
Nadine Sellier, Elodie Guettier, and Christophe Staub / American Journal of Agricultural Science and Technology

(2014) Vol. 2 No. 2 pp. 74-99

- $\quad$ Mid-peripheral temperature: assumed to be an intermediate position between body core and peripheral or surface sites. Measurements realized with microchips implanted intramuscularly, or at a depth of more than two centimeters from the skin, will be placed in this group.

- $\quad$ Peripheral or surface temperature: measurements obtained from the animal's skin, coat, eyes, udder, legs, ears, and those realized by microchips implanted at a depth of less than two centimeters from the skin will be placed in this category.

These three areas will be applied to all stages of all species studied in this work.

\section{Technical Section: the Most Common Systems to Measure Temperature Continuously without Restraining the Subject}

A short overview of the main types of sensors which may be used for continuous recording of body temperature is now discussed. There are two focuses to this discussion: first, the actual temperature sensors are compared. Next, the process of transmission of data is reviewed, including the entire group of media required for this process, such as transmitter, receiver/decoder and data acquisition unit. Each of these technologies has advantages and disadvantages related to their range and autonomy. These differences are taken into account in order to compare which system would be ideal for each specific purpose and context of use. The key features of the various systems currently used for remotely measuring temperature are shown in Tables 1 and 2. This paper focused on two main groups of existing technologies for measuring temperature, those technologies which operate through direct contact such as thermocouples or thermistors which are generally embedded in a data logger, those technologies which do not require any contact with the subject in order to take a measurement and are instead based on infrared sensors.

\subsection{Contact measurement media}

Thermocouples are based on the thermoelectric effect discovered by Seebeck in 1821, who found that when two dissimilar metals at different temperature were joined, a voltage was produced. Thermocouples measure temperature by generating a small voltage signal proportional to the temperature difference between the junctions of the two dissimilar metals. One junction (the hot junction) is typically encased in a sensor probe at the point of measurement; the other junction (the cold junction) is connected to the measuring instrument. With relatively high risk of errors, thermocouple systems need continual re-calibration. Although thermocouples are the only option for validating extreme temperatures, there is an alternative system that is more suited to mid-range temperatures measurements: thermistors.

Thermistors, which are far more accurate and stable than thermocouples, are semiconductors made from metal oxides that are pressed into a small bead, disk, wafer, or other shape and sintered at high temperatures (www.national.instruments). The thermistors sense temperature because temperature is related to their electrical resistance; when placed inside a small data recorder, they are ideal for standalone operations such as thermal mapping. Designed for more limited temperature ranges than thermocouples, they offer numerous advantages such as greater accuracy and long-term in-calibration performance. Data recorders can provide temperature accuracies to $0.1^{\circ} \mathrm{C}$ (Bull, 2008). Although a major disadvantage of thermistors is that they are non-linear, this 
Nadine Sellier, Elodie Guettier, and Christophe Staub / American Journal of Agricultural Science and Technology

(2014) Vol. 2 No. 2 pp. 74-99

complication can easily be corrected using the thermistor's datasheet, which places a lookup table inside the microcontroller that will match the voltages with their corresponding temperatures (Parekh, 2010). To date, the majority of animal or human telemetric measures of temperature are made through thermistors. The transmission media is based on electromagnetic waves that are modulated and demodulated; the output of the sensor, or transducer, is modulated to a form which can be transmitted wirelessly over a distance from the animal to a receiver, using an embedded transmitter. The received signal is demodulated and the measured variable extracted through proper signal conditioning and calibration by the data acquisition system (Hamrita and Paulishen, 2011).

\subsection{No-contact measurement media}

In contrast to the previous categories of sensors that need direct contact with the tissue to take temperature measurements, infrared (IR) technology does not require any contact with the animal, allowing remote measuring. Physical basis of IR thermography is linked to the fact that any object that has a temperature above absolute zero $\left(-273.15{ }^{\circ} \mathrm{C}\right.$ or $\left.0{ }^{\circ} \mathrm{K}\right)$ emits infrared radiation, and the temperature of the object will determine the wavelength of the radiation emitted. At biologically relevant temperatures, radiation peaks in the infrared wavelength range of approximately 8 to 12 $\mu \mathrm{m}$, (McCafferty et al., 2011 and 2013). Principles of IR thermometry are presented in Tables 1 and 2. To determine an object's temperature, the emissivity of the object must be known. Emissivity is defined as the ratio between the emissive power of the body surface at any wavelength and the emissive power of a blackbody at the same temperature. A "blackbody" is an idealized physical body that absorbs all incident electromagnetic radiation. This means that while a true black body would have an emissivity value of 1 , any other object, known as a "grey body", would have an emissivity value of less than 1 (www.ictinternational). Emissivity varies as a function of temperature and surface finish for materials. For industrial purposes, tables of materials' emissivity are published as a guide for relative or delta measurements, but the exact emissivity of a material should be determined when absolute measurements are required. These exact measurements may be determined by comparison of the infrared thermometer reading and a standard contact thermometer reading from the same surface (www.ictinternational.com.au).

For the past five to ten years, technology for thermal method of temperature measurement has developed considerably, and companies are now able to produce a variety of devices to respond to many diverse uses of temperature measurements, ranging from industrial to medical and veterinary purposes. To measure temperature on animals, two types of infrared systems are commercially available, IR thermometers and thermal cameras.

IR thermometers are made of a lens which focuses the infrared thermal radiation onto a detector, which converts the radiant power into an electrical signal that can be displayed in units of temperature after the ambient temperature is compensated for. Spot infrared thermometer, or infrared pyrometer, measures the temperature at a spot on the surface of the animal. This spot is a relatively small area determined by the distance-to-spot-ratio, which is the ratio of the distance to the object to the diameter of the temperature measurement area. For instance if the D:S ratio is $12: 1$, measuring the temperature of an object 12 inches $(30 \mathrm{~cm})$ away will average the temperature over a 1-inch-diameter $(25 \mathrm{~mm})$ area. The sensor may have an adjustable emissivity setting, which can be set to measure the temperature of reflective (shiny) or non-reflective surfaces. 
Nadine Sellier, Elodie Guettier, and Christophe Staub / American Journal of Agricultural Science and Technology

(2014) Vol. 2 No. 2 pp. 74-99

Infrared thermal imaging cameras, or infrared cameras, are essentially infrared radiation thermometers that measure the temperature at many points over a relatively large area in order to generate a two-dimensional image called thermogram, in which each pixel represents a temperature. This technology is more processor- and software-intensive than spot or scanning thermometers and is used for monitoring large areas. Infrared cameras allow measuring the temperature of an individual in its environment (Tattersall and Cadena, 2010 Poikalainen et al., 2012).

\subsection{Discussion about the different methods to measure remote temperature}

When considering the varity of purposes that producers may have for remote temperature measurement devices, it can be quite difficult to choose between the available systems. There are two primary categories available to produces, contact themometry based on thermocouples or thermistors probes and distance thermomemetry based on IR radiations emitted by the subject. However, these two types of temperature measurement systems do not allow the user to obtain the same nature of information, as they do not explore the same physiological fields. Currently, there are many companies developing these technologies for improved use. An example of this development is the technique of "Zero Heat Flow" which allows to measure core temperature at the skin surface using contact thermistors. Basically, a ZHF sensor insulates the skin locally, ensuring the skin surface is heated to deep body temperature and creating a region of zero heat flow from the body core to the skin. Typical body locations for ZHF sensors have low skinfold thickness and few large veins, such as the sternum, forehead and occipital region of the head (Yamakage et al., 2002; Teunissen et al., 2011).

Regarding telemetric contact devices, the most important constraint is the management of energy, which has impacts on both essential criteria that are the size of the device implanted or ingested by the animal and the distance of emission of the data. When the primary selection criterion is the size of the sensor, it will be necessary for the user to make concessions for measuring distances. In that case, as the sensor cannot be equipped with a battery, communication with the sensor will have to be made by using an antenna placed near the animal. The power consumption of the device increases proportionally with the intended transmission range, the sensor sampling frequency and the data transmission rate. Those parameters have to be taken into consideration and compromises will have to be made specific to the research project according to scientific interest. Alternative possibilities exist, such as external power supplies for biotelemetry sensors made with inductive energy supplies based on magnetic coupling. Another option is conserving power is to adapt a sensor with a microprocessor operating in sleep mode except when data is being collected using on-chip memory. A very clear and detailed review of a large variety of telemetric devices marketed or adapted by scientific users is made by Hamrita and Paulishen (2011). The issue of multiregistration is discussed and technological systems allowing researchers interested to record a large variety of data such as temperature, ECG and activity on each animal, or one specific measure on a entire group of animals, are mentioned (Hamrita and Paulishen, 2011). Moreover, wireless sensor technologies allow different network topologies, cooperative capabilities, and multihop communication protocoles, that radio frequency identification systems do not allow (Ruiz-Garcia et al., 2009). 
Another type of question has to be considered in the context of telemetric measurement of temperature; it relates to the great number of data that will be generated during each study. A more sophisticated device will have more programmable capabilities. The data acquisition of the temperature system must be interfaced with a computer, in order to provide a user-friendly interface for the producer to control the measurements and the storage of the collected data.

When using IR devices for temperature measurement, precautions need to be taken to ensure the best adapted devices, proper usage, and appropriate image interpretation. Infrared technology is quite a complex field. Environmental conditions (solar radiations, humidity) must be considered, as they are impacting both the quality of the transmission of infrared waves emitted by the animal but also the quality of the reception of the waves. With a low spatial resolution at distance and an influence of the viewing angle, the infra red thermometer or camera must be well located and controlled (McCafferty, 2013). The accuracy of the measure is closely associated with the settings of the emissivity of the coat or the plumage, which is generally assumed to be close to that of the blackbody, but may be modified by dirtiness or wetness of the coat. A review of these weaknesses is made by McCafferty et al., (2011).

A great attention must be paid to the area where the measurement will be performed when using remote temperature measurement with infrared devices. It is the key to obtain comparable and repeatable data within a period of time. Researchers (Hoffmann et al., 2012; Schaefer et al., 2012) have adapted automatic devices for temperature recording using a software comparing pictures in order to obtain reliable data.

Special attention must also be paid to the metrological aspect of the measurement process. To obtain accurate, correct and repeatable results, sensors and devices must be calibrated with a known standard of thermometry in order to ensure conformity (Brown-Brandl et al., 2003; Marsh et al., 2008; Versey et al., 2011).

Beyond the technical advantages and disadvantages of the two methods compared here (infrared vs thermocouples and thermistances), the site to measure temperature is closely related to the phenomenon to study. To date, these two types of methods are not appropriate for all temperature measurements, since they are distinguished by the fact that one system measures the surface temperature while the other measures the internal temperature of the animal. In addition, technical issues remain, since the contact sensors are still more or less invasive methods. For some species, non invasive ingestion of sensors can allow only limited time to measure. Subcutaneous microchips, placement in the animal may be constrained by the need to recover the implant to prevent introduction into the food supply. 
Nadine Sellier, Elodie Guettier, and Christophe Staub / American Journal of Agricultural Science and Technology (2014) Vol. x No. x pp. xx

Table 1 Physical characteristics of the main sensors for remote body temperature measurement

\begin{tabular}{|c|c|c|c|c|c|}
\hline & & Thermocouples & Thermistances & Infra Red Thermometer & Infra Red Camera \\
\hline \multirow[t]{4}{*}{ Sensors } & $\begin{array}{l}\text { Principles } \\
\text { of physics }\end{array}$ & $\begin{array}{c}\text { A thermocouple is created } \\
\text { when two dissimilar metals } \\
\text { touch. A Seebeck voltage ( } 5 \text { to } \\
6 \mathrm{mV} \text { at } 100^{\circ} \mathrm{C} \text { ) changes } \\
\text { linearly with temperature } \\
\text { variation. } \\
\text { (www.national.instruments; } \\
\text { Bergquist, } \\
\text { www.burnsengineering.com) }\end{array}$ & $\begin{array}{c}\text { A thermistor is } \\
\text { semiconductor made from } \\
\text { metal oxides. Its resistance } \\
\text { varies significantly with } \\
\text { temperature. } \\
\text { Thermistors have a high } \\
\text { sensitivity }\left(\sim 200 \Omega /{ }^{\circ} \mathrm{C}\right) \\
\text { (www.national.instruments) }\end{array}$ & \multicolumn{2}{|c|}{$\begin{array}{l}\text { At the specific wavelength the total emissive power of the } \\
\text { body is: } \\
\qquad P=\varepsilon \bullet \sigma \cdot A \bullet T^{4} \text { where } \\
-\varepsilon \text { monochromatic emissivity of the material. } \\
\text { - } \sigma \text { : Stefan-Boltzmann constant }(5.67 \times 10-8 \mathrm{Wm}-2 \mathrm{~K}-4) \text {, } \\
\text { - A: area of the actual surface from which radiation is } \\
\text { registered, } \\
\text { - T: absolute temperature of body surface (Poikalainen et al., } \\
\text { 2012) } \\
\text { (www.infratec.de; www.ictinternational.com.au) }\end{array}$} \\
\hline & Accuracy & $\begin{array}{l}\text { Accuracy at } 0^{\circ} \mathrm{C}: \text { Standard } \\
\text { limits: } \pm 4^{\circ} \mathrm{C} \\
\text { Special limits: } \pm 2^{\circ} \mathrm{C}\end{array}$ & $\begin{array}{l}\text { In a thermistor-based } \\
\text { system, a signal of } 35 \mathrm{mV} \\
\text { per }{ }^{\circ} \mathrm{C} \text { is typical. Very stable } \\
\text { measuring system. Its high } \\
\text { resistivity produces a typical } \\
\text { error of } 0.05^{\circ} \mathrm{C}\end{array}$ & $2^{\circ} \mathrm{C}$ or $0.5 \%$ & $\begin{array}{l}<0.1^{\circ} \mathrm{C} \pm 2 \% \text { of full } \\
\text { temperature range. For } \\
\text { better accuracy }\left(<0.05^{\circ} \mathrm{C}\right) \\
\text { use a cooled camera }\end{array}$ \\
\hline & Range & $-267^{\circ} \mathrm{C}$ to $2316^{\circ} \mathrm{C}$ & $-100^{\circ} \mathrm{C}$ to $500^{\circ} \mathrm{C}$ & \multicolumn{2}{|c|}{ From $-25^{\circ} \mathrm{C}$ to $100^{\circ} \mathrm{C}$ (for animal temperature purposes) } \\
\hline & $\begin{array}{l}\text { Calibration/ } \\
\text { stability }\end{array}$ & $\begin{array}{l}\text { Unstable : need to be calibrate } \\
\text { before and after every single } \\
\text { test run. }\end{array}$ & Stable & \multicolumn{2}{|c|}{$\begin{array}{c}\text { Need to be calibrated with a object of known temperature, or } \\
\text { combine with contact thermometer (when emissivity is } \\
\text { unknown). }\end{array}$} \\
\hline
\end{tabular}


Nadine Sellier, Elodie Guettier, and Christophe Staub / American Journal of Agricultural Science and Technology (2014) Vol. 2 No. 2 pp. 74-99

Table 2 Comparison of the constraints for field use of the main devices for remote body temperature measurement in livestock

\begin{tabular}{|c|c|c|c|c|}
\hline & Thermocouples & Thermistances & Infra Red Thermometer & Infra Red Camera \\
\hline $\begin{array}{l}\text { Environ- } \\
\text { mental } \\
\text { constraints }\end{array}$ & \multicolumn{2}{|c|}{ No influence of environmental constraints } & \multicolumn{2}{|c|}{$\begin{array}{l}\text { Influenced by ambient radiations, dust, local temperature and } \\
\text { humidity, any obstacle on the path of radiations (ex: glass, window } \\
\text { untreated). Influence of hygrometry may therefore be problematic } \\
\text { for studies in the field, (Mc Cafferty, 2007). }\end{array}$} \\
\hline \multirow{2}{*}{$\begin{array}{l}\text { Precautions } \\
\text { to be taken } \\
\text { to use } \\
\text { correctly } \\
\text { the sensor }\end{array}$} & $\begin{array}{l}\text { Thermocouples are less } \\
\text { accurate, stable and sensitive } \\
\text { than thermistances. They read } \\
\text { only relative temperature } \\
\text { difference between the tip and } \\
\text { the leads while thermistors read } \\
\text { absolute temperature. }\end{array}$ & $\begin{array}{l}\text { Thermistors are fragile and } \\
\text { have a limited range. They } \\
\text { require a current source, could } \\
\text { experience self heating, and are } \\
\text { nonlinear. }\end{array}$ & \multirow{2}{*}{\multicolumn{2}{|c|}{$\begin{array}{l}\text { Ratio distance/surface is mentioned for all opticals (technical } \\
\text { datasheets) and must be respected (optical resolution). } \\
\text { Angle : For a surface with emissivity of } 0.98 \text {, the associated } \\
\text { temperature error has been shown to be independent of viewing } \\
\text { angle up to } 30^{\circ} \text { but increased from } 0.5 \text { to } 3^{\circ} \mathrm{C} \text { at } 30-70^{\circ} \text { and is } \\
\text { greater than } 4^{\circ} \mathrm{C} \text { at angles above } 70^{\circ}(\mathrm{McCafferty}, 2007 \text { ) } \\
\text { Emissivity must be adjusted. Bare skin has an emissivity of } 0.98 \\
\text { and the emissivity of dry fur is relatively uniform in mammals, in } \\
\text { the range } 0.98-1.0 \text {. The emissivity of the coat can also be changed } \\
\text { by dirt or other materials (e.g. soil = } 0.93-0.96 \text { or water = 0.96), } \\
\text { (Mc Cafferty, 2007). } \\
\text { Wavelength : must be chosen according to the object of interest } \\
\text { Optical: Possible choice of the most suitable lens: wide-angle or } \\
\text { telephoto lens }\end{array}$}} \\
\hline & \multicolumn{2}{|c|}{$\begin{array}{l}\text { Need to be compared to a reference thermometer and be calibrated } \\
\text { regularly. }\end{array}$} & & \\
\hline Distance & \multicolumn{2}{|c|}{ Contact } & \multicolumn{2}{|c|}{ From a few meters to $3000 \mathrm{~m}$ (and more) } \\
\hline $\begin{array}{l}\text { Response } \\
\text { Time }\end{array}$ & $\begin{array}{r}\mathrm{Ba} \\
\text { bat }\end{array}$ & $\begin{array}{l}\text { Bare thermistors in a well stirred oil } \\
\text { bath will have a } 63 \% \text { response time of } \\
1 \text { second (www.omega.com) }\end{array}$ & \multicolumn{2}{|c|}{ From $1 \mathrm{~ms}$ to $250 \mathrm{~ms}$} \\
\hline
\end{tabular}


Nadine Sellier, Elodie Guettier, and Christophe Staub / American Journal of Agricultural Science and Technology (2014) Vol. 2 No. 2 pp. 74-99

Table 3 Publication references related with deep core temperature measurements in livestock

\begin{tabular}{|c|c|c|c|c|c|c|}
\hline Animal & $\begin{array}{l}\text { Sensor position / } \\
\text { targeted organ }\end{array}$ & $\begin{array}{l}\text { Sensor } \\
\text { technic }\end{array}$ & Aim & $\begin{array}{c}\text { Design } \\
\text { (Individuals } \\
\text { / Duration) }\end{array}$ & Sensor model / Company & Reference \\
\hline Bovine & Reticulum & Thermistor & $\mathrm{V} / \mathrm{P}$ & $\mathrm{C} 4 / \mathrm{M}$ & CTMS / MaGiiX Inc. & Bewley et al. (2008) \\
\hline Bovine & Rumen & Thermistor & $\mathrm{V} / \mathrm{R}$ & $\mathrm{C} 2 / \mathrm{M}$ & SmartStock LLC & Cooper-Prado et al. (2011) \\
\hline Bovine & Rumen & Thermistor & $\mathrm{V}$ & $\mathrm{C} 1 / \mathrm{D}$ & Cow TempTM / Innotek & Prendiville et al. (2003) \\
\hline Bovine & Rumen & Thermistor & $\mathrm{V}$ & $\mathrm{C} 1 / \mathrm{W}$ & SmartStock LLC & O AlZahal et al. (2009) \\
\hline Bovine & Rectal & Thermistor & $\mathrm{V}$ & $\mathrm{C} 1 / \mathrm{H}$ & TidbiT v2 / Onset Corp. & Reuter et al. (2010) \\
\hline Bovine & Abdo. cavity & Thermistor & $\mathrm{V}$ & C1 / D & CorTemp / HQInc. & Brown-Brandl et al. (2003) \\
\hline Bovine & Eardrum & Thermistor & V & $\mathrm{C} 1 / \mathrm{D}$ & Teagasc - Silsoe Institutes & Prendiville et al. (2003) \\
\hline Bovine & Eardrum & Thermistor & $\mathrm{P} / \mathrm{TR} / \mathrm{N}$ & $\mathrm{C} 2 / \mathrm{D}$ & Stowaway XTI / Onset & Mader et al. (2010) \\
\hline Bovine & Eardrum & Thermistor & $\mathrm{P} / \mathrm{TR}$ & $\mathrm{C} 2 / \mathrm{M}$ & Stowaway XTI / Onset & Mader and Kreikemeier (2006) \\
\hline Bovine & Eardrum & Thermistor & $\mathrm{V}$ & $\mathrm{C} 1 / \mathrm{M}$ & Steri-Probe / Cincinnatti Sub-Zero & Bergen and Kennedy (2000) \\
\hline Bovine & Eardrum & Thermistor & $\mathrm{P} / \mathrm{N}$ & $\mathrm{C} 2 / \mathrm{D}$ & Stowaway XTI / Onset & Davis et al. (2003) \\
\hline Bovine & Vaginal & Thermocouple & $\mathrm{V} / \mathrm{R}$ & $\mathrm{C} 2 / \mathrm{D}$ & L820 / Unipulse Inc. & Aoki et al. (2005) \\
\hline Bovine & Vaginal & Thermistor & $\mathrm{P} / \mathrm{N}$ & $\mathrm{C} 2 / \mathrm{M}$ & ACR Systems Inc. & Burke et al. (2007) \\
\hline Bovine & Vaginal & Thermistor & $\mathrm{V}$ & $\mathrm{C} 1 / \mathrm{M}$ & Wildlife MaterialsInc. & Bergen and Kennedy (2000) \\
\hline Bovine & Vaginal & Thermistor & G & $\mathrm{C} 3 / \mathrm{W}$ & HOBO Pro V2 / Onset & Dikmen et al. (2009) \\
\hline
\end{tabular}


Nadine Sellier, Elodie Guettier, and Christophe Staub / American Journal of Agricultural Science and Technology (2014) Vol. 2 No. 2 pp. 74-99

\begin{tabular}{|c|c|c|c|c|c|c|}
\hline Bovine & Vaginal & Thermistor & $\mathrm{V} / \mathrm{WB}$ & $\mathrm{C} 1 / \mathrm{W}$ & TX minilog / Vemco Ltd. & Stewart et al. (2007) \\
\hline Bovine & Vaginal & Thermistor & $\mathrm{V} / \mathrm{H}$ & $\mathrm{C} 1 / \mathrm{D}$ & DSTmicro-T. / Star-Oddi & Burdick et al. (2012) \\
\hline Porcine & $\begin{array}{l}\text { Eardrum- Artery- } \\
\text { Bladder }\end{array}$ & Thermistor & $\mathrm{V}$ & $\mathrm{C} 1 / \mathrm{D}$ & cSteri-Probe / Cincinnati & Hanneman et al. (2004) \\
\hline Ovine & Abdo. cavity & Thermistor & $\mathrm{P} / \mathrm{TR}$ & $\mathrm{C} 2 / \mathrm{H}$ & Mini-Mitter / Datamed & Laburn et al. (2002) \\
\hline Ovine & Eardrum / Pinna & Thermistor & $\mathrm{P} / \mathrm{TR}$ & $\mathrm{C} 2 / \mathrm{D}$ & Temptag / HortResearch & Lowe et al. (2001) \\
\hline Ovine & Vaginal & Thermistor & $\mathrm{P} / \mathrm{TR}$ & $\mathrm{C} 2 / \mathrm{D}$ & Free-Range Monitor / HortResearch & Lowe et al. (2001) \\
\hline Caprine & Abdominal cavity & Thermistor & $\mathrm{P} / \mathrm{TR}$ & $\mathrm{C} 1 / \mathrm{M}$ & $150 \mathrm{MHz} /$ Datamed & Faurie et al. (2001) \\
\hline Equine & Digestive tract & Thermistor & $\mathrm{V}$ & $\mathrm{C} 1 / \mathrm{D}$ & Cortemp / HQ Inc. & Green et al. (2005) \\
\hline Equine & Jugular vein & Thermistor & $\mathrm{V}$ & $\mathrm{C} 1 / \mathrm{D}$ & Betatherm & Green et al. (2005) \\
\hline Poultry & Digestive tract & Thermistor & $\mathrm{V}$ & $\mathrm{C} 1 / \mathrm{H}$ & CorTemp / HQInc. & Brown-Brandl et al. (2003) \\
\hline Poultry & Gizzard & Thermistor & $\mathrm{P} / \mathrm{TR}$ & $\mathrm{C} 2 / \mathrm{D}$ & CBT sensor / HQI Tech. & Green and Xin (2009) \\
\hline Poultry & Abdominal cavity & Thermistor & $\mathrm{V}$ & $\mathrm{C} 1 / \mathrm{W}$ & 23 K 3 D 300 / Betatherm & Kettlewell et al. (1997) \\
\hline Rabbit & Eardrum & IR & $\mathrm{V}$ & $\mathrm{C} 2 / \mathrm{H}$ & IRT-3520 / Braun or Pet-Temp / A M & Chen and White (2006) \\
\hline Canine & Digestive tract & $\begin{array}{c}\text { Quartz } \\
\text { oscillator }\end{array}$ & $\mathrm{V}$ & $\mathrm{C} 2 / \mathrm{H}$ & COR-100 / Human Tech. & Angle and Gillette (2011) \\
\hline Human & Forehead & Zero Heat Flow & $\mathrm{V}$ & $\mathrm{C} 1 / \mathrm{H}$ & NICCT sensor patch / Philips & Teunissen et al. (2011) \\
\hline Human & Vaginal & Thermistor & $\mathrm{V}$ & - & MA100 NTC thermistor & Caldeira et al. (2010) \\
\hline
\end{tabular}

Abbreviations used for the Aims: G for Genetics, $\mathrm{H}$ for Health, $\mathrm{V}$ for Method Validation, $\mathrm{N}$ for Nutrition, $\mathrm{P}$ for Physiology, R for Reproduction, TR for thermoregulation, WB for Well-being.

Abbreviations used for the number of animals involved in the Experimental Design: Class number ranging from C1 ( $<10)$, C2 (10 to 50), C3 (50 to 100) and C4 (>100). Abbreviations used for the duration of the trial: H (hours), D (days), W (weeks) and M (months). 
Nadine Sellier, Elodie Guettier, and Christophe Staub / American Journal of Agricultural Science and Technology (2014) Vol. 2 No. 2 pp. 74-99

Table 4 Publication references related with mid-peripheral temperature measurements in livestock

\begin{tabular}{|c|c|c|c|c|c|c|}
\hline Animal & $\begin{array}{l}\text { Sensor position / } \\
\text { targeted organ }\end{array}$ & $\begin{array}{l}\text { Sensor } \\
\text { technic }\end{array}$ & Aim & $\begin{array}{c}\text { Design } \\
\text { (Individuals / } \\
\text { Duration) }\end{array}$ & Sensor model / Company & Reference \\
\hline Bovine & Sub cutaneous & Thermistor & $\mathrm{V} / \mathrm{TR} / \mathrm{H}$ & $\mathrm{C} 1 / \mathrm{M}$ & Microchips / Digital Angel Corp. & Reid et al. (2012) \\
\hline Porcine & Sub-cutaneous & Thermistor & $\mathrm{H} / \mathrm{V}$ & $\mathrm{C} 2 / \mathrm{W}$ & IPTT-300м / Plexx & Lohse et al. (2010) \\
\hline Caprine & Sub-cutaneous & Thermistor & $\mathrm{H} / \mathrm{V}$ & $\mathrm{C} 1 / \mathrm{W}$ & BioThermo / Identipet & Torrao et al. (2011) \\
\hline Equine & Sub-cutaneous & Thermistor & $\mathrm{P} / \mathrm{TR} / \mathrm{R}$ & $\mathrm{C} 1 / \mathrm{M}$ & Microchips / Digital Angel Corp. & Mawyer et al. (2012) \\
\hline Equine & Sub-cutaneous & Thermistor & V & $\mathrm{C} 1 / \mathrm{H}$ & TX1400 B / Digital Angel Inc. & Marsh et al. (2008) \\
\hline Rabbit & Sub cutaneous. & Thermistor & $\mathrm{V}$ & $\mathrm{C} 2 / \mathrm{H}$ & IPTT-200 / BioMedic Data Syst. & Chen and White (2006) \\
\hline
\end{tabular}

Abbreviations used for the Aims: G for Genetics, H for Health, V for Method Validation, N for Nutrition, P for Physiology, R for Reproduction, TR for thermoregulation, WB for Well-being

Abbreviations used for the number of animals involved in the Experimental Design: Class number ranging from C1 ( $<10)$, C2 (10 to 50 ), C3 (50 to 100) and C4 (>100). Abbreviations used for the duration of the trial: H (hours), D (days), W (weeks) and M (months). 
Nadine Sellier, Elodie Guettier, and Christophe Staub / American Journal of Agricultural Science and Technology (2014) Vol. 2 No. 2 pp. 74-99

Table 5 Publications references related with surface temperature measurements in livestock

\begin{tabular}{|c|c|c|c|c|c|c|}
\hline Animal & $\begin{array}{l}\text { Sensor position / } \\
\text { targeted organ }\end{array}$ & Sensor technic & Aim & \begin{tabular}{|c|} 
Design \\
(Individuals \\
/ Duration)
\end{tabular} & Sensor Model / Company & Reference \\
\hline Bovine & Eardrum & Thermistor & $\mathrm{H}$ & $\mathrm{C} 4 / \mathrm{M}$ & FeverTags / Fever Tags LLC & Richeson et al. (2012) \\
\hline Bovine & Eye & IR camera & $\mathrm{P} / \mathrm{WB}$ & $\mathrm{C} 2 / \mathrm{H}$ & S60 / FLIR & Stewart et al. (2010) \\
\hline Bovine & Eye & IR camera & $\mathrm{P} / \mathrm{WB}$ & $\mathrm{C} 2 / \mathrm{H}$ & S60 / FLIR & Stewart et al. (2008) \\
\hline Bovine & Eye & IR camera & $\mathrm{V} / \mathrm{H}$ & $\mathrm{C} 2 / \mathrm{W}$ & 760 / FLIR & Schaefer et al. (2004) \\
\hline Bovine & Eye & IR camera & $\mathrm{V}$ & $\mathrm{C} 1 / \mathrm{W}$ & S60 / FLIR & Stewart et al. (2007) \\
\hline Bovine & Eye-Cheek-Nose-Back & IR camera & $\begin{array}{c}\mathrm{P} / \mathrm{N} / \\
\mathrm{G}\end{array}$ & $\mathrm{C} 3 / \mathrm{M}$ & TM SC2000 / FLIR & Montanholi et al. (2010) \\
\hline Bovine & Eye-Flank-Hooves & IR camera & $\mathrm{V}$ & $\mathrm{C} 3 / \mathrm{W}$ & 760 / FLIR & Schaefer et al. (2012) \\
\hline Bovine & Foot - Eye & IR camera & $\mathrm{V}$ & C3 / D & $\begin{array}{c}\text { EX320 / FLIR or IRFlexCam R1 / } \\
\text { Fluke }\end{array}$ & Rainwater-Lovett et al. (2009) \\
\hline Bovine & Skin-Eye-Ear-Vulva & IR camera & V & $\mathrm{C} 2 / \mathrm{D}$ & OPTRIS $®$ PI 160 / Optris & Hoffmann et al. (2012) \\
\hline Bovine & Skin & IR thermometer & $\mathrm{V}$ & $\mathrm{C} 3 / \mathrm{H}$ & IR thermometer / Oakton Instr. & Pusta et al. (2012) \\
\hline Bovine & Hoof & IR camera & $\mathrm{H} / \mathrm{V}$ & $\mathrm{C} 2 / \mathrm{W}$ & Jenoptik VarioCam / InfraTec & Alsaaod and Buescher (2012) \\
\hline Bovine & Hoof & IR camera & $\mathrm{V}$ & $\mathrm{C} 2 / \mathrm{D}$ & 760 / FLIR & Nikkhah et al. (2007) \\
\hline Bovine & Pinna & IR thermometer & $\mathrm{P} / \mathrm{TR}$ & $\mathrm{C} 2 / \mathrm{M}$ & Raynger 3i / Raytek & Mader and Kreikemeier (2006) \\
\hline Bovine & Udder - Legs - Flank & IR camera & $\mathrm{V}$ & $\mathrm{C} 3 / \mathrm{H}$ & Fluke TiS / Fluke & Poikalainen et al. (2012) \\
\hline Bovine & Udder & IR camera & $\mathrm{H} / \mathrm{V}$ & $\mathrm{C} 2 / \mathrm{W}$ & 760 / FLIR & Berry et al. (2003) \\
\hline
\end{tabular}


Nadine Sellier, Elodie Guettier, and Christophe Staub / American Journal of Agricultural Science and Technology (2014) Vol. 2 No. 2 pp. 74-99

\begin{tabular}{|c|c|c|c|c|c|c|}
\hline Bovine & Udder & IR camera & $\mathrm{V}$ & $\mathrm{C} 3 / \mathrm{H}$ & FlexCam S / Infraredsolutions Inc. & Polat et al. (2010) \\
\hline Porcine & Skin & IR camera & $\mathrm{V}$ & $\mathrm{C} 2 / \mathrm{H}$ & ST20 Pro / Raytek & Chung et al. (2010) \\
\hline Porcine & Back and Flank & Thermocouple & $\mathrm{P} / \mathrm{TR}$ & $\mathrm{C} 3 / \mathrm{M}$ & HH-21 / Omega & Renaudeau et al. (2008) \\
\hline Porcine & Vulva & IR camera & $\mathrm{V} / \mathrm{R}$ & $\mathrm{C} 2 / \mathrm{W}$ & S60 / FLIR & Sykes et al. (2012) \\
\hline $\begin{array}{c}\text { Caprine, } \\
\text { Equine, } \\
\text { Bovine, } \\
\text { Ovine }\end{array}$ & Skin-Thigh-Pinna & Thermistor & $\mathrm{P} / \mathrm{TR}$ & C1 / D & $\begin{array}{l}\text { GM103 / Bowthorpe } \\
\text { Thermometrics }\end{array}$ & Piccione et al. (2005) \\
\hline Ovine & Eye. Legs. Flank. Belly & IR camera & $\mathrm{P} / \mathrm{TR}$ & $\mathrm{C} 2 / \mathrm{M}$ & 900 / AGEMA & Al-Ramamneh et al. (2011) \\
\hline Equine & Eye & IR camera & V & $\mathrm{C} 2 / \mathrm{D}$ & EX320 / FLIR & Johnson et al. (2011) \\
\hline Poultry & Eye - Crest & IR camera & WB & $\mathrm{C} 2 / \mathrm{W}$ & E4 / FLIR & Edgar et al. (2011) \\
\hline Poultry & Feet & IR camera & $\mathrm{H} / \mathrm{V}$ & $\mathrm{C} 4 / \mathrm{H}$ & PM695 / FLIR & Wilcox et al. (2009) \\
\hline Poultry & Comb & IR camera & WB & $\mathrm{C} 1 / \mathrm{H}$ & A40 / FLIR & Moe et al. (2012) \\
\hline Rabbit & Ear / Thigh & IR thermometer & V & $\mathrm{C} 2 / \mathrm{H}$ & IR therm. / Raytek Raynger & Chen and White (2006) \\
\hline
\end{tabular}

Abbreviations used for the Aims: G for Genetics, $\mathrm{H}$ for Health, $\mathrm{V}$ for Method Validation, $\mathrm{N}$ for Nutrition, P for Physiology, R for Reproduction, TR for thermoregulation, WB for Well-being

Abbreviations used for the number of animals involved in the Experimental Design: Class number ranging from C1 (<10), C2 (10 to 50), C3 (50 to 100) and C4 (>100). Abbreviations used for the duration of the trial: H (hours), D (days), W (weeks) and M (months). 


\section{Biological Section: Bibliographic Review on Remote Temperature Measurement on Livestock}

For this review, a literature search was undertaken using ISI Web of Knowledge (http://apps.webofknowledge.com/) and the CAB Abstracts data base (www.cabi.org). Results included a wide range of species of agronomic interest. Articles older than 13 years (before 2000) were discarded from this review. The publication list is therefore not exhaustive but it covers a large proportion of the primary domains of husbandry practices and research. For the purpose of this review, studies reporting human information related to clinical applications were also considered to provide a perspective for future avenues of research. The results of the studies are organized to allow the reader to find technical and bibliographical references as easily as possible, by type of temperature measurement method, by type of animal species and by site of measurement localization. These results are presented in Tables 3, 4 and 5.

Remote temperature measurement is facing a number of difficulties which depend on the location at which the measurement is taken. The fact that physiologic function causes changes in temperature and the level of invasiveness of the device are the two major points to be considered. The contact sensors, which are likely to assess the core temperature of the body, are split into two categories, those that are surgically implanted and those that are not surgically implanted. The sensors that are not surgically implanted may be ingested, placed in the vagina or rectum, or placed in the ear canal to measure the temperature of the eardrum. Surgically implated sensors, which are used on fully or locally anesthetized animals, are injected under the skin, deeper into muscle or the adipose tissue, or placed in the peritoneal cavity. Thermal sensors can also be positioned in the arteries, but this technology that is still based on wired devices, is very difficult to use with animals and will therefore not be addressed here.

\subsection{Temperature measurement with non invasive contact sensors}

As non invasive contact sensors are mainly thermistors used for deep core temperature measurements, references will principally be placed in Table 3.

When sensors are ingested, the duration of temperature measurement is constrained by the gastrointestinal function in monogastric animals. However, the time taken for ingested objects to transit through the whole gastrointestinal tract may be sufficient for research purpose as in the studies of Angle and Gillette (2011) on Labrador dogs, or of Green et al. (2005) on horses, or finally of Brown-Brandl et al. (2003) and Green and Xin (2009) on laying hens.

In ruminants, sensors are blocked either in the rumen or in the reticulum leading to unequivalent measurments according to Bewley et al., (2008). Schutz and Bewley (2009), through a large literature review, present the diversity of tests performed and results obtained from a bolus thermometer placed in the rumen. The study also describes the advantages of ingestion sensors and their limitations. The biggest disadvantages of the method are measurement variations related to the ingestion of water and food which will induce sudden temperature modifications. Those modifications will depend on the temperature and volume of ingested water, the qualitative and 
Nadine Sellier, Elodie Guettier, and Christophe Staub / American Journal of Agricultural Science and Technology

(2014) Vol. 2 No. 2 pp. 74-99

quantitative composition of the food and nature of the forage (Prendiville et al., 2003; 0. AlZahal et al., 2009 and 2011; Burdick et al., 2012). In addition, some temperature variations may also be observed due to the position of the animal, for example lying on a cold floor. Sensors placed in the rumen are less likely to reflect changes in body temperature.

Intravaginal sensors exhibit a good correlation with the rectal temperature and are shown to be more sensitive to small variations in temperature if correctly positioned as depth positioning will influence the measurement. Using intravaginal devices, Burdick et al. (2012) were able to detect an immune response of heifers, following a LPS (lipo poly saccharide) challenge, and Dikmen et al. (2009) to highlight the effects of heterosis on the resistance to heat stress in dairy cows. In addition, Burke et al. (2007) was able to demonstrate the circadian rhythm of temperature through the use of intravaginal sensors. In 2001, Lowe et al. (2001) had used vaginal sensors in sheep to demonstrate changes in body temperature in relation to external conditions, activity and circadian rhythm.

Since rectal temperature is considered the reference, researchers have adapted devices for cows such as Reuter et al. (2010) or for horses Green et al. (2005) in order to record temperature continuously and automatically.

The use of a sensor in the ear canal in contact with the eardrum is another non-invasive method to monitor body temperature, which is well correlated with rectal temperature. Using tympanic temperature measurements, Prendiville et al. (2003) and Mader et al. (2005 and 2010) showed the effects of food on body temperature variations in cattle. Davis et al. (2003) used this method to detect heat stress. This method was applied on sheep as well, by Lowe et al. (2001) in order to follow the circadian rhythm. An original device was presented by Richeson et al. (2012) for the early detection of bovine repiratory disease in grazing animals; this device flashes an indicator light when tympanic temperature is over $39.8^{\circ} \mathrm{C}$. However, the long term use of this method is not recommended as there are important risks of ear infection (Bergen and Kennedy, 2000). Moreover, this location is difficult to reach in other species, due to matters of anatomy (Hanneman et al., 2004).

Very few studies were found with the use of contact thermistor or thermocouple for surface temperature measurement (Richeson et al., 2012) however, the studies that were found are recorded on Table 5. In these studies, methods were not telemetric but they allowed Lowe et al. (2001) to illustrate an interaction between meteorological conditions and circadian rhythm in pastoral sheep, Piccione et al. (2005) to study the circadian rhythm pattern of goat, sheep, cattle and horse temperature, and Renaudeau et al. (2008) to define a thermal circulation index between body core and skin, which varied in relation with heat stress.

\subsection{Temperature measurement with invasive contact sensors}

Since it is common to place invasive contact sensors sub-cutaneously, publications that were found using these materials are recorded on Table 4. For long-term studies, core temperature can be continuously monitored through use of contact sensors placed in the peritoneal cavity. In this case, the necessity of surgical intervention limits the number of animals involved in the experimentation. In particular, Laburn et al. (2002) and Faurie et al. (2001) on sheep and goats respectively (Table 
Nadine Sellier, Elodie Guettier, and Christophe Staub / American Journal of Agricultural Science and Technology

(2014) Vol. 2 No. 2 pp. 74-99

3), used this method to monitor the temperature variations of the fetus in utero, in relation to heat stress applied to the mother. Kettlewell et al. (1997) inserted sensors in the abdominal cavity of chickens, in order to study the response to heat stress (Table 3).

The use of subcutaneous biotelemetric sensors raises different potential difficulties. The positioning area of the sensor must be precise and must prevent possible future migrations. Installation of subcutaneous biotelemetric sensors assumes that the system is suitable for the animal studied (Marsh et al., 2008). Subcutaneous temperature is function of core temperature and external environment. Subcutanous temperature may therefore be variable, then not suitable for early detection of a disease (Lohse et al., 2010). In goats exposed to different environmental conditions, the temperature measured by microchips implanted at various body locations differed from core temperature (Torrao et al., 2011). Similar results are obtained in steers by Reid et al. (2012), (Table 4).

\subsection{Temperature measurement with non invasive - no contact sensors}

No-contact sensors mean surface temperature measurement only and references that were found using these materials are placed in Table 5. The development of techniques for measuring body temperature by IR is rapidly growing and bibliography on the implementation of these methods in husbandry or experimentation is rich. Knizkova et al. (2007) presents a review of research studies carried out between the years 1985 and 2005. These studies demonstrate the potential uses of IRT for various species of agronomic interest, in the areas of health and well-being of animals as well as meat quality prediction. These studies compare surface temperature measurement sites with body core temperature assesed through rectal measurements, with the aim of early detection of diseases, inflammations, stress or pain.

For example, eye temperature IR measurements are correlated with core temperature and its variations. In cattle, Stewart et al. (2008 and 2010) validated non invasive assessment of eye temperature for studying stress and pain. McCafferty (2013) confirmed the use of eye temperature measurements on poultry combining his results with temperature measurements of the crest. Edgar et al. (2011) and Moe et al. (2012), demonstrated with IR thermography that drop in temperature of the comb of hens is correlated with emotions (pleasure, fear).

Potential uses of the IR method for the early detection of diseases in cattle are studied by many authors (Schaefer et al., 2004; Hoffmann et al., 2012 ; Poikalainen et al., 2012), the latter proposing a fully automated system of measurement installed close to the livestock waterers. Montano et al. (2009) showed that the IR technique, especially on the extremities of the body, is relevant to the study of feed efficiency of steers. This method is suitable for studies focused on the impact of external conditions on the thermoregulation abilities of cattle, whether the measurements are taken from the skin (Pusta et al., 2012) or the udder (Berry et al., 2003). However, infrared thermography is of limited suitability for evaluating changes in the metabolic rate caused by shearing because this system only measures radiative heat loss, not total nonevaporative heat loss (Autio, 2008; Al-Ramamneh et al., 2011). Recently, Johnson et al. (2011) reported that IR eye temperature measurement alone are unable to predict core temperature in the horse model. 
Nadine Sellier, Elodie Guettier, and Christophe Staub / American Journal of Agricultural Science and Technology

(2014) Vol. 2 No. 2 pp. 74-99

Early detection of mastitis is a particularly important objective, for both health and economic reasons. The use of IR technology to measure the udder temperature has resulted in more controversial results. Schutz and Bewley (2009) did not validate this method unlike Berry et al. (2003) and Kunc et al. (2007) who found interest of udder surface infrared thermography for mastitis detection. These outcomes are comparable with those obtained for the early detection of leg injuries or lameness in horses or cattle, in which the studies' conclusions diverged. In horses, Eddy et al. (2001) and Head and Dyson (2001), expressed reservations about the ability of IR thermography to detect lameness, while Nikkhah et al. (2005) and Poikalainen et al. (2012) recognized this method in cattle to detect injuries on legs, hooves or other body parts. An approach in the interpretation of the images dependent on symmetry, thermal pattern between the left and right sides, should lead to more effective assessment of hoof lesions (Alsaaod and Buescher, 2012) or in horses' back or legs injuries (Robson, 2010 and 2011; Cetinkaya and Demirutku, 2012). These divergent results emphasize the strict standards necessary during the implementation of IR temperature measurement. In addition to the adapted choices and settings of the materials and technical specifications, a set of external factors must be taken into account when taking measurements (these precautions are summarized in Table 2) since the temperature measured by IR reflects the surface temperature of the animal, which is dependent on its internal body temperature and the external conditions such as ambient temperature, humidity, air speed, solar radiations, and hot or cold radiations from the walls around the animal at the time of measurement. All these potential bias are recommended to be controlled in order to obtain reliable, accurate and repeatable results, as pointed out by Sykes et al. (2012), who faced these problem when studying sexual status of gilts. The controlling and recording of all these parameters is then essential to further exploitation of the results.

\section{Discussion}

The objective of this bibliographic study was to inform future users and researchers of the existence of previous work in the field of remote temperature measurement. The review cannot be exhaustive, but the present publication may give an overview of the many possibilities of these novel technologies. Chiefly the goal of the present work was to draw users' attention to the limitations and precautions which are necessary, and help future users to choose the most appropriate device for their purpose. Innovative technical solutions for remote measurements of animals will be produced from the close collaboration of biologists with specialists in physical measurements, telecommunications and data processing.

This study focused on the tools and methods for body temperature measurement and its variations in livestock. The present review highlighted that first studies had the purpose of monitoring early detection of diseases or thermoregulatory responses to thermal stress. One third of the found references aimed at validating the measurement tools implemented and to identify the better correlated sites than rectal temperature to measure the animal's core temperature when the animal is at basal balance condition (Chen et al., 2006).

Validation of measurement methods is often based on a health challenge with LPS (Lipo Poly Saccaride) or another known pathogen inoculated to the animals (Berry et al., 2003; Schaefer et al., 2004; Richeson et al., 2012). Health challenges are also often based on heat stress (Renaudeau et al., 2008; Green and Xin, 2009). 
Nadine Sellier, Elodie Guettier, and Christophe Staub / American Journal of Agricultural Science and Technology

(2014) Vol. 2 No. 2 pp. 74-99

Due to the scarcity of publications on reproduction or nutrition and remote temperature sensing, it appears that body temperature is not a critical measurement in these fields. Body temperature variations involved in these biological functions are subtle compared to the accuracy currently available in thermometry. Then, body temperature is not the most reliable trait to assess reproduction or nutrition functions. In contrast, precocious detections of diseases or heat stresses are of major interest to farmers. Early detection of problems prevents risks for spreading to other animals and reduce technical and economical drop of performances. Technologies allowing early detection of diseases and heat stress are subjected to a strong demand, which is apparent through the proportion of publications on this topic.

As a consequence of the current technical development, remote measurement of body temperature in livestock will become essential in future years for monitoring herds within precision farming. These technologies will allow researchers to emancipate from biases induced by experimenters measuring act variability. In a survey (Schutz and Bewley, 2009), professionals in milk production were asked to define and classify their expectations from biotelemetry. Heat stress, mastitis detection and oestrus detection were listed as primary goals, whereas metritis, respiratory diseases, well-being and pregnancy diagnoses were listed as secondary goals. Biotelemetric temperature, as well as other physiological parameters, is of central interest in the field of highspeed phenotyping of livestock. Many other physiological real-time records have to be combined with temperature to fully describe physiological status or responses of livestock animals. As a response to these new demands, technologic breakthroughs and significant advances have been made in instrumentation, development and miniaturization of new biotelemetry devices. Thanks to Wireless sensor technology, Micro-Electro-Mechanical Systems Sensors (MEMS) are now coupled with signal conditioning and radio units to form "motes". Then motes are small, low-cost, lowpower requirements computers monitoring one or more Mems-type sensors. These MEMS include inertial, pressure, temperature, humidity, strain-gage, and various piezo and capacitive transducers for proximity, position, velocity, acceleration and vibration measurements (Güler and Ubeyli, 2002; Ruiz-Garcia et al., 2009; Hamrita et al. 2011). MEMS will allow users to assess physiological or behavioral features such as ECG, cardiac frequency, respiration frequency, activity or resting, rumination, $\mathrm{pH}$, glycemia, oxygen saturation, hematocrit, and to integrate time-related variations of these parameters. Significant advances are underway in order to improve powering and battery capacity by using circulating glucose as an complementary energy source (Rapoport et al., 2012). Diversification of wireless communication tools (Bluetooth, Wifi, Zigbee, DECT: Digital enhanced cordless telecommunications), with new specifications, will also contribute to the development of telemetry. Implementation of digital images processing algorithms and dynamic IR imaging will continue to increase and to develop.

\section{Conclusion}

Implementation of remotely measured body temperature in animals is faced with many difficulties both at biological and technological levels. The rapid progress of technology in this area will provide powerful tools for researchers but will not exempt users from the necessity of considering the appropriateness of the measurement site in relation to a physiological question to answer.

The contribution of these techniques for the study of biology is no longer to be proved. Many authors confirm that telemetric temperature measurements may allow earlier detection of health 
Nadine Sellier, Elodie Guettier, and Christophe Staub / American Journal of Agricultural Science and Technology

(2014) Vol. 2 No. 2 pp. 74-99

problems, such as infectious or inflammatory diseases. These technologies help to highlight and study circadian and sexual rhythms. They also contribute to a improved assessment of animal welfare by providing continuous monitoring. Finally, they are new tools to study stress or pain felt by livestock animals. A number of innovations will come from human medical research, from sportive purposes, which already are at the cutting-edge of the exploration of these new areas and marketed devices connected with mobile phone applications. In the field of agricultural research, the challenge will be to transfer these technologies and innovations to animal facilities. Those new integrated technologies will develop in order to respond to the various demands of both scientists and farmers for precision farming and remote monitoring.

\section{Acknowledgments}

The authors wish to thank colleagues from INRA, Eric Bobillier, Alain Ducos and Pierre-Yves Lebail for their helpful discussion, Michael Bertolo (INRA) and Sandra Martin (Texas A\&M University) for English proofreading.

\section{References}

Al-Ramamneh, D., Gerken, M., Gerken, D.M., \& Riek, A. (2011). Effect of shearing on water turnover and thermobiological variables in German Blackhead mutton sheep. Journal of Animal Science, 89, 4294-4304. http://dx.doi.org/10.2527/jas.2011-3982

Alsaaod, M., \& Buescher, W. (2012). Detection of hoof lesions using digital infrared thermography in dairy cows. Journal of Dairy Science, 95, 735-742. http://dx.doi.org/10.3168/jds.2011-4762

AlZahal, O., Steele, M.A., Valdes, E.V., \& McBride, B.W. (2009). Technical note: the use of a telemetric system to continuously monitor ruminal temperature and to predict ruminal $\mathrm{pH}$ in cattle. Journal of Dairy Science, 92, 5697-5701. http://dx.doi.org/10.3168/ids.2009-2220

Al-Zahal, O., Al-Zahal, H., Steele, M.A., Schaik, M., van Kyriazakis, I., Duffield, T.F., \& McBride, B.W. (2011). The use of a radiotelemetric ruminal bolus to detect body temperature changes in lactating dairy cattle. Journal of Dairy Science, 94, 3568-3574. http://dx.doi.org/10.3168/ids.2010-3944

Angle, T.C., \& Gillette, R.L. (2011). Telemetric measurement of body core temperature in exercising unconditioned Labrador retrievers. Canadian Journal of Veterinary Research, 75, 157-159.

Aoki, M., Kimura, K., \& Suzuki, O. (2005). Predicting time of parturition from changing vaginal temperature measured by data-logging apparatus in beef cows with twin fetuses. Animal Reproduction Science, 86, 112. http://dx.doi.org/10.1016/j.anireprosci.2004.04.046

Autio, E., Heiskanen, M.L., \& Mononen, J. (2007). Thermographic evaluation of the lower critical temperature in weanling horses. Journal of Applied Animal Welfare Science, 10(3), 207-216. http://dx.doi.org/10.1080/10888700701353493

Autio, E. (2008). Loose Housing of Horses in a Cold Climate. Thesis PhD, University of Kuopio, FINLAND.

Bergen, R.D., \& Kennedy, A.D. (2000). Relationship between vaginal and tympanic membrane temperature in beef heifers. Canadian Journal of Animal Science, 80, 515-518. http://dx.doi.org/10.4141/A00-033

Berry, R.J., Kennedy, A.D., Scott, S.L., Kyle, B.L., \& Schaefer, A.L. (2003). Daily variation in the udder surface temperature of dairy cows measured by infrared thermography: potential for mastitis detection. Canadian Journal of Animal Science, 83, 687-693. 
Nadine Sellier, Elodie Guettier, and Christophe Staub / American Journal of Agricultural Science and Technology (2014) Vol. 2 No. 2 pp. 74-99

http://dx.doi.org/10.4141/A03-012

Bewley, J.M., Einstein, M.E., Grott, M.W., \& Schutz, M.M. (2008). Comparison of reticular and rectal core body temperatures in lactating dairy cows. Journal of Dairy Science, 91, 4661-4672. http://dx.doi.org/10.3168/jds.2007-0835

Brown-Brandl, T.M., Yanagi, T., Xin, H., Gates, R.S., Bucklin, R.A., \& Ross, G.S. (2003). A new telemetry system for measuring core body temperature in livestock and poultry. Applied Engineering in Agriculture, 19(5), 583-589.

Bull, K. (2008). Thermistors and thermocouples. Matching the tool to the task in thermal validation. Journal of ValidationTechnology, 14, 73-76.

Burdick, N.C., Carroll, J.A., Dailey, J.W., Randel, R.D., Falkenberg, S.M., \& Schmidt, T.B. (2012). Development of a self-contained, indwelling vaginal temperature probe for use in cattle research. Journal of Thermal Biology, 37, 339-343. http://dx.doi.org/10.1016/i.jtherbio.2011.10.007

Burke, N.C., Scaglia, G., Saker, K.E., Blodgett, D.J., \& Swecker, W.S. (2007). Influence of endophyte consumption and heat stress on intravaginal temperatures, plasma lipid oxidation, blood selenium, and glutathione redox of mononuclear cells in heifers grazing tall fescue. Journal of Animal Science, 85, 2932-2940. http://dx.doi.org/10.2527/jas.2007-0303

Caldeira, J.M.L.P., Rodrigues, J.J.P.C., Garcia, J.F.R., \& de la Torre, I. (2010). A new wireless biosensor for intravaginal temperature monitoring. Sensors, 10, 10314-10327. http://dx.doi.org/10.3390/s101110314

Cetinkaya, M.A., \& Demirutku, A. (2012). Thermography in the assessment of equine lameness. Turkish Journal of Veterinary and Animal Sciences, 36, 43-48.

Chen, P.H., \& White, C.E. (2006). Comparison of rectal, microchip transponder, and infrared thermometry techniques for obtaining body temperature in the laboratory rabbit (Oryctolagus cuniculus). Journal of the American Association for Laboratory Animal Science, 45, 57-63.

Chung, T., Jun, W., Nam, E.H., Kim, J., Park, S., \& Hwang, C.Y. (2010). Comparison of Rectal and Infrared Thermometry for Obtaining Body Temperature of Gnotobiotic Piglets in Conventional Portable Germ Free Facility. Asian-Australasian Journal of Animal Science, 23, 1364-1368. http://dx.doi.org/10.5713/ajas.2010.90507

Cooper-Prado, M.J., Long, N.M., Wright, E.C., Goad, C.L., \& Wettemann, R.P. (2011). Relationship of ruminal temperature with parturition and estrus of beef cows. Journal of Animal Science, 89, 1020-1027. http://dx.doi.org/10.2527/jas.2010-3434

Davis, M.S., Mader, T.L., Holt, S.M., \& Parkhurst, A.M. (2003). Strategies to reduce feedlot cattle heat stress: effects on tympanic temperature. Journal of Animal Science, 81, 649-661.

Dikmen, S., Martins, L., Pontes, E., \& Hansen, P.J. (2009). Genotype effects on body temperature in dairy cows under grazing conditions in a hot climate including evidence for heterosis. International Journal of Biometeorology, 53, 327-331. http://dx.doi.org/10.1007/s00484-009-0218-3

Eddy, A.L., Van Hoogmoed, L.M., \& Snyder, J.R. (2001). The role of thermography in the management of equine lameness. The Veterinary Joumal, 162, 172-181. http://dx.doi.org/10.1053/tvjl.2001.0618

Edgar, J.L., Lowe, J.C., Paul, E.S., \& Nicol, C.J. (2011). Avian maternal response to chick distress. Proceedings of the Royal Society Biological Science (Vol. 278). http://dx.doi.org/10.1098/rspb.2010.2701

Eigenberg, R.A., Brown-Brandl, T.M., \& Nienaber, J.A. (2008). Sensors for dynamic physiological measurements. Computer and Electronics in Agriculture, 62(1), 41-47. http://dx.doi.org/10.1016/i.compag.2007.08.011

Faurie, A.S., Mitchell, D., \& Laburn, H.P. (2001). Feto-maternal relationships in goats during heat and cold exposure. Experimental Physiology, 86, 199-204. http://dx.doi.org/10.1113/eph8602152 
Nadine Sellier, Elodie Guettier, and Christophe Staub / American Journal of Agricultural Science and Technology (2014) Vol. 2 No. 2 pp. 74-99

Green, A.R., Gates, R.S., \& Lawrence, L.M. (2005). Measurement of horse core body temperature. Journal of Thermal Biology, 30, 370-377. http://dx.doi.org/10.1016/i.jtherbio.2005.03.003

Green, A.R., \& Xin, H. (2009). Effects of Stocking Density and Group Size on Thermoregulatory Responses. American Society of Agricultural and Biological Engineers, 52(6), 2033-2038.

Güler, N.F., \& Ubeyli, E.D. (2002). Theory and applications of biotelemetry. Journal of Medical Systems, 26, 159-178. http://dx.doi.org/10.1023/A:1014862027454

Hamrita, T.K., \& Paulishen, M. (2011). Advances in management of poultry production using biotelemetry. In Modern Telemetry (eds Dr. Ondrej Krejcar, Croatia), vol 8, pp. 165-182.

Hamrita, T.K., Kaluskar, N.P., \& Wolfe, K.L. (2005). Advances in smart sensor technology. Conference Record of the 2005 IEEE Industry Applications Conference, New York, (Volumes 1-4, pp.2059-2062).

Hanneman, S.K., Jesurum-Urbaitis, J.T., \& Bickel, D.R. (2004). Comparison of methods of temperature measurement in swine. Laboratory Animals, 38, 297-306. http://dx.doi.org/10.1258/002367704323133682

Head, M.J., \& Dyson, S. (2001). Taking the temperature of equine thermography. Veterinary Journal, 162, 166167. http://dx.doi.org/10.1053/tvjl.2001.0639

Hoffmann, G., Schmidt, M., Ammon, C., Rose-Meierhöfer, S., Burfeind, O., Heuwieser, W., \& Berg, W. (2012). Monitoring the body temperature of cows and calves using video recordings from an infrared thermography camera. Veterinary Research Communication, 37(2), 91-99. http://dx.doi.org/10.1007/s11259-012-9549-3

Hogewerf, P.H. (2012). Smart Dairy Farming: care for individual cows. 38th International Committee for Animal Recording, Cork, Ireland.

Johnson, S.R., Rao, S., Hussey, S.B., Morley, P.S, \& Traub-Dargatz, J.L. (2011). Thermographic eye temperature as an index to body temperature in ponies. Journal of Equine Veterinary Science, 31, 63-66. http://dx.doi.org/10.1016/i.jevs.2010.12.004

Kunc, R., Knizkova, I., Prikryl, M., \& Maloun, J. (2007). Infrared thermography as a tool to study the milking process: a review. Agricultura Tropica et Subtropica, 40 (1).

Knízková, I., Kunc, P., Gürdil, G.A.K., Pinar, Y., \& Selvi, K.Ç. (2012). Applications of Infrared Thermography in animal production. Anadolu Journal of Agricultural Sciences, 22, 329-336.

Kettlewell, P.J., Mitchell, M.A., \& Meeks, I.R. (1997). An implantable radio-telemetry system for remote monitoring of heart rate and deep body temperature in poultry. Computers and Electronics in Agriculture, $17,161-175$. http://dx.doi.org/10.1016/S0168-1699(96)01302-6

Laburn, H.P., Faurie, A., Goelst, K., \& Mitchell, D. (2002). Effects on fetal and maternal body temperatures of exposure of pregnant ewes to heat, cold, and exercise. Journal of applied physiology, 92, 802-808.

Lohse, L., Uttenthal, A., Enøe, C., \& Nielsen, J. (2010). A study on the applicability of implantable microchip transponders for body temperature measurements in pigs. Acta Veterinaria Scandinavica, 52- 29.

Lowe, T.E., Cook, C.J., Ingram, J.R., \& Harris, P.J. (2001). Impact of climate on thermal rhythm in pastoral sheep. Physiology and Behaviour, 74, 659-664. http://dx.doi.org/10.1016/S0031-9384(01)00608-4

Mader, T.L., Davis, M.S., \& Kreikemeier, W.M. (2005). Tympanic temperature and behavior associated with moving feedlot cattle. Professional Animal Scientist, 21, 339-344.

Mader, T.L., \& Kreikemeier, W.M. (2006). Effects of growth-promoting agents and season on blood metabolites and body temperature in heifers. Journal of Animal Science, 84, 1030-1037.

Mader, T.L., Gaughan, J.B., Johnson, L.J., \& Hahn, G.L. (2010). Tympanic temperature in confined beef cattle exposed to excessive heat load. International Journal of Biometeorology, 54, 629-635. http://dx.doi.org/10.1007/s00484-009-0229-0 
Nadine Sellier, Elodie Guettier, and Christophe Staub / American Journal of Agricultural Science and Technology (2014) Vol. 2 No. 2 pp. 74-99

Marsh, J.R., Gates, R.S., Day, G.B., Aiken, G.E., \& Wilkerson, E.G. (2008). Assessment of an injectable RFID temperature sensor for indication of horse well-being. 37th International Livestock Environment Symposium, Iguassu Falls, Brazil.

Mawyer, J.D., Cavinder, C.A., Vogelsang, M.M., Sigler, D.H., Love, C.C., Brinsko, S.P., Blanchard, T.L., Varner, D.D., Arnold, C.E., Teague, S., \& Gordon, R.K. (2012). Thermoregulation of the testicle in response to exercise and subsequent effects on semen characteristics of stallions. Journal of Animal Science, 90, 2532-2539. http://dx.doi.org/10.2527/jas.2011-4543

Mccafferty, D.J. (2007). The value of infrared thermography for research on mammals: previous applications and future directions. Mammal Revue, 37, 207-223. http://dx.doi.org/10.1111/j.1365-2907.2007.00111.x

McCafferty, D.J., Gilbert, C., Paterson, W., Pomeroy, P.P., Thompson, D., Currie, J.I., \& Ancel, A. (2011). Estimating metabolic heat loss in birds and mammals by combining infrared thermography with biophysical modelling. In Comparative Biochemistry and Physiology, Part A Molecular and Integrative Physiology (Vol. 158, pp. 337-345). http://dx.doi.org/10.1016/i.cbpa.2010.09.012

McCafferty, D.J. (2013). Applications of thermal imaging in avian science. International Journal of Avian Science, 155, 4-15.

Moe, R.O., Stubsjøen, S.M., Bohlin, J., Flø, A., \& Bakken, M. (2012). Peripheral temperature drop in response to anticipation and consumption of a signaled palatable reward in laying hens (Gallus domesticus). Physiology and Behaviour, 106, 527-533. http://dx.doi.org/10.1016/i.physbeh.2012.03.032

Montanholi, Y.R., Swanson, K.C., Palme, R., Schenkel, F.S., McBride, B.W., Lu, D., \& Miller, S.P. (2010). Assessing feed efficiency in beef steers through feeding behavior, infrared thermography and glucocorticoids. Animal, 4, 692-701. http://dx.doi.org/10.1017/S1751731109991522

Montano, N., Porta, A., Cogliati, C., Costantino, G., Tobaldini, E., Casali, K.R., \& Lellamo, F. (2009). Heart rate variability explored in the frequency domain: a tool to investigate the link between heart and behavior. Neuroscience and Biobehavioural Reviews, 33, 71-80. http://dx.doi.org/10.1016/i.neubiorev.2008.07.006

Nikkhah, A., Plaizier, J.C., Einarson, M.S., Berry, R.J., Scott, S.L., \& Kennedy, A.D. (2005). Short communication: Infrared thermography and visual examination of hooves of dairy cows in two stages of lactation. Journal of Dairy Science, 88, 2749-2753. http://dx.doi.org/10.3168/jds.S0022-0302(05)72954-4

Piccione, G., Caola, G., \& Mortola, J.P. (2005). Scaling the daily oscillations of breathing frequency and skin temperature in mammals. In Comparative Biochemistry and Physiology, Part A Molecular and Integrative Physiology (Vol. 140, pp. 477-486). http://dx.doi.org/10.1016/i.cbpb.2005.02.010

Poikalainen, V., Praks, J., Veermae, I., \& Kokin, E. (2012). Infrared temperature patterns of cow's body as an indicator for health control at precision cattle farming. Agronomy Research, 10(1), 187-194.

Polat, B., Colak, A., Cengiz, M., Yanmaz, L.E., Oral, H., Bastan, A., Kaya, S., \& Hayirli, A. (2010). Sensitivity and specificity of infrared thermography in detection of subclinical mastitis in dairy cows. Journal of Dairy Science, 93, 3525-3532. http://dx.doi.org/10.3168/ids.2009-2807

Prendiville, D.J., Lowe, J., Earley, B., Spahr, C., \& Kettlewell, P. (2003). Radiotelemetry systems for measuring body temperature in cattle. Farm and Food 13. Beef Production Series (Vol. 57, project No. 4806).

Pusta, D., Sobolu, R., \& Pasca, I. (2012). Determination of the cutaneous temperature by infrared thermometry in Holstein cows. Bulletin of University of Agricultural Sciences and Veterinary Medicine Cluj-Napoca, 69, 190-194.

Rainwater-Lovett, K., Pacheco, J.M., Packer, C., \& Rodriguez, L.L. (2009). Detection of foot-and-mouth disease virus infected cattle using infrared thermography. Veterinary Journal, 180, 317-324. http://dx.doi.org/10.1016/j.tvil.2008.01.003 
Nadine Sellier, Elodie Guettier, and Christophe Staub / American Journal of Agricultural Science and Technology (2014) Vol. 2 No. 2 pp. 74-99

Rapoport, B.I., Kedzierski, J.T., \& Sarpeshkar, R. (2012). A Glucose Fuel Cell for Implantable Brain-Machine Interfaces. Plos One, 7(6), e38436. http://dx.doi.org/10.1371/journal.pone.0038436

Reid, E.D., Fried, K., Velasco, J.M., \& Dahl, G.E. (2012). Correlation of rectal temperature and peripheral temperature from implantable radio-frequency microchips in Holstein steers challenged with lipopolysaccharide under thermoneutral and high ambient temperatures. Journal of Animal Science, 90, 4788-4794. http://dx.doi.org/10.2527/jas.2011-4705

Renaudeau, D., Kerdoncuff, M., Anais, C., \& Gourdine, J.L. (2008). Effect of temperature level on thermal acclimation in Large White growing pigs. Animal, 2, 1619-1626. http://dx.doi.org/10.1017/S1751731108002814

Renaudeau, D., Anais, C., Tel, L., \& Gourdine, J.L. (2010). Effect of temperature on thermal acclimation in growing pigs estimated using a nonlinear function. Journal of Animal Science, 88, 3715-3724. http://dx.doi.org/10.2527/jas.2009-2169

Reuter, R.R., Carroll, J.A., Hulbert, L.E., Dailey, J.W., \& Galyean, M.L. (2010). Development of a self-contained, indwelling rectal temperature probe for cattle research. Journal of Animal Science, 88, 3291-3295. http://dx.doi.org/10.2527/jas.2010-3093

Richeson, J.T., Powell, J.G., Kegley, E.B., \& Hornsby, J.A. (2012). Evaluation of an ear-mounted tympanic thermometer device for bovine respiratory disease diagnosis. Arkansas Agricultural Experimental Station. Research Series, 597, 40-42.

Robson, J.L. (2010). Horses In Color : The Role of Thermal Imaging in the Equine Industry.

Robson, J.L. (2011). Back to Reality: Infrared Thermography (IRT) as an Objectifier of Equine Back Pain and Saddle-fitting Problems.

Ruiz-Garcia, L., Lunadei, L., Barreiro, P., \& Ignacio Robla, J. (2009). A Review of Wireless Sensor Technologies and Applications in Agriculture and Food Industry: State of the Art and Current Trends. Sensors, 9, 47284750. http://dx.doi.org/10.3390/s90604728

Schaefer, A.L., Cook, N., Tessaro, S.V., Deregt, D., Desroches, G., Dubeski, P.L., Tong, A.K.W., \& Godson, D.L. (2004). Early detection and prediction of infection using infrared thermography. Canadian Journal of Animal Science, 84, 73-80. http://dx.doi.org/10.4141/A02-104

Schaefer, A.L., Cook, N.J., Bench, C., Chabot, J.B., Colyn, J., Liu, T., Okine, E.K., Stewart, M., \& Webster, J.R. (2012). The non-invasive and automated detection of bovine respiratory disease onset in receiver calves using infrared thermography. Research in Veterinary Science, 93, 928-935. http://dx.doi.org/10.1016/i.rvsc.2011.09.021

Schutz, M.M., \& Bewley, J.M. (2009). Implications of Changes in Core Body Temperature. In Proceedings of the Tri-State Dairy Nutrition Conference, Fort Wayne, Indiana, (pp. 39-54).

Stewart, M., Webster, J.R., Verkerk, O.A., Schaefer, A.L., Colyn, J.J., \& Stafford, K.J. (2007). Non-invasive measurement of stress in dairy cows using infrared thermography. Physiology and Behaviour, 92, 520 525. http://dx.doi.org/10.1016/i.physbeh.2007.04.034

Stewart, M., Stafford, K.J., Dowling, S.K., Schaefer, A.L., \& Webster, J.R. (2008). Eye temperature and heart rate variability of calves disbudded with or without local anaesthetic. Physiology and Behaviour, 93, 789-797. http://dx.doi.org/10.1016/i.physbeh.2007.11.044

Stewart, M., Verkerk, G.A., Stafford, K.J., Schaefer, A.L., \& Webster, J.R. (2010). Noninvasive assessment of autonomic activity for evaluation of pain in calves, using surgical castration as a model. Journal of Dairy Science, 93, 3602-3609. http://dx.doi.org/10.3168/ids.2010-3114

Sykes, D.J., Couvillion, J.S., Cromiak, A., Bowers, S., Schenck, E., Crenshaw, M., \& Ryan, P.L. (2012). The use of digital infrared thermal imaging to detect estrus in gilts. Theriogenology, 78,147-152. http://dx.doi.org/10.1016/i.theriogenology.2012.01.030 
Nadine Sellier, Elodie Guettier, and Christophe Staub / American Journal of Agricultural Science and Technology

(2014) Vol. 2 No. 2 pp. 74-99

Tattersall, G.J., \& Cadena, V. (2010). Insights into animal temperature adaptations revealed through thermal imaging. Imaging Science Journal, 58, 261-268. http://dx.doi.org/10.1179/136821910X12695060594165

Teunissen, L.P.J., Klewer, J., de Haan, A., de Koning, J.J., \& Daanen, H.A.M. (2011). Non-invasive continuous core temperature measurement by zero heat flux. Physiological Measurement, 32, 559-570. http://dx.doi.org/10.1088/0967-3334/32/5/005

Torrao, N.A., Hetem, R.S., Meyer, L.C.R., \& Fick, L.G. (2011). Assessment of the use of temperature-sensitive microchips to determine core body temperature in goats. Veterinary Record, 168, 328. http://dx.doi.org/10.1136/vr.c6200

Versey, N.G., Gore, C.J., Halson, S.L., Plowman, J.S., \& Dawson, B.T. (2011). Validity and reliability of temperature measurement by heat flow thermistors, flexible thermocouple probes and thermistors in a stirred water bath. Physiological Measurement, 32, 1417-1424. http://dx.doi.org/10.1088/0967-3334/32/9/005

Wilcox, C.S., Patterson, J., \& Cheng, H.W. (2009). Use of thermography to screen for subclinical bumblefoot in poultry. Poultry Science, 88, 1176-1180. http://dx.doi.org/10.3382/ps.2008-00446

Yamakage, M., Iwasaki, S., \& Namiki, A. (2002). Evaluation of a newly developed monitor of deep body temperature. Journal of Anesthesia, 16, 354-357.

http://dx.doi.org/10.1007/s005400200056 